\title{
Innovative Agents for Actinic Keratosis and Nanocarriers Enhancing Skin Penetration
}

\author{
M. Schäfer-Korting ${ }^{a} \quad$ M. Höltje ${ }^{b} \quad$ H.C. Korting ${ }^{c} \quad$ H.-D. Höltje ${ }^{b}$ \\ a Institut für Pharmazie (Pharmakologie und Toxikologie) der Freien Universität Berlin, Berlin, \\ ${ }^{\mathrm{b}}$ Institut für Pharmazeutische und Medizinische Chemie, Heinrich-Heine-Universität Düsseldorf, Düsseldorf, und \\ 'Klinik und Poliklinik für Dermatologie und Allergologie der Ludwig-Maximilians-Universität, München, Deutschland
}

\section{Key Words}

DNA polymerase $\alpha \cdot$ Nucleosides P Polymerase

inhibitors $\cdot$ Skin cancer $\cdot$ Solid lipid nanoparticles •

Core-multishell nanotransporters

\begin{abstract}
Actinic keratosis and cutaneous squamous cell carcinoma are of increasing importance with aging and increased ultraviolet light exposure in Western societies. Efficient and welltolerated therapy is still a matter of concern. As with tumours of other organs, new target sites and innovative drugs selectively addressing them are widely looked for. Due to the relevance for DNA synthesis and thus cell proliferation, human DNA polymerase $\alpha$ should be such a target, the more so as the three-dimensional structure of the active site has been proposed based on the application of molecular modelling methods and molecular dynamics simulations. The modelled structure of the active site was used for docking nucleotide analogues in order to design selective inhibitors. Consequently, well-fitting thymidine and guanosine analogues were synthesized and tested in vitro for their influence on normal and transformed human keratinocytes. In fact, the combination of modelling studies and in vitro tests allowed us to design antiproliferative and cytotoxic agents which are new drug candidates for the therapy of skin tumours, given
\end{abstract}

the agents are no relevant substrates of nucleotide transporters (MRP-4, MRP-5) expressed by skin cancer cells. Essential kinases for nucleoside activation were detected, too, corresponding with the observed effects of nucleoside analogues. Due to the rather high molecular weight and poor solubility, however, skin penetration should be poor and thus topical therapy may require carriers to improve the uptake. This becomes feasible by lipidic and non-lipidic nanoparticles which can enhance the uptake of lipophilic agents up to 13 -fold.

Copyright $\odot 2010$ S. Karger AG, Basel

\section{Introduction}

Due to aging and in particular because of an increased ultraviolet (UV) exposure in Western societies, the number of patients with actinic keratosis (carcinoma in situ) and cutaneous squamous cell carcinoma is increasing dramatically. UV-induced DNA damage results in C-to$\mathrm{T}$ transitions at bipyrimidine sites, e.g. in the p53 gene [1]. Recently, the progression of actinic keratosis into squamous cell carcinoma due to human papillomavirus (HPV) infection has been described (for a review, see Madkan et al. [2]). Patients with actinic keratosis proved to be more frequently positive for HPV (37 vs. 0\%), and

\section{KARGER}

Fax +41613061234 E-Mail karger@karger.ch www.karger.com (c) 2010 S. Karger AG, Basel

$1660-5527 / 10 / 0231-0006 \$ 26.00 / 0$

Accessible online at:

www.karger.com/spp
Prof. Dr. M. Schäfer-Korting

Institut für Pharmazie der Freien Universität Berlin

Königin-Luise-Strasse $2+4$

DE-14195 Berlin (Germany)

Tel. +4930838 53283,Fax+4930838 54399, E-Mail msk@zedat.fu-berlin.de 
lesions removed by laser treatment more frequently recurred, if positive for herpesvirus [3]. HPV positivity is particularly high (82\%) in actinic keratosis lesions of immunosuppressed renal transplant recipients [1]. HPV prevalence is also found increased in squamous cell carcinoma lesions of UV-irradiated SKH transgenic mice [4].

Current therapy of actinic keratosis, however, can be painful and of insufficient efficacy as with 5-fluorouracil (5-FU) cream [5] and photodynamic therapy using the UV sensitizer 5-aminolevulinic acid or its methyl ester prodrug $[6,7]$, or cure rates are not fully sufficient as with 5-FU applied as a polymeric microsponge preparation [5]. Carcinoma in situ therapy is not fully efficient either with diclofenac/hyaluronic acid $[8,9]$, which is reported to inhibit overexpressed cyclooxygenase- 2 in these tumours, or imiquimod, which stimulates the non-specific immune response by Toll-like receptor interaction [10].

Therefore, alternative approaches like interference with DNA synthesis are under investigation. The human DNA polymerase $\alpha$ (pol $\alpha$ ) catalyzes the central step in DNA replication and therefore is an interesting target. In fact, the nucleoside pol $\alpha$ inhibitor gemcitabine is already used systemically for pancreas carcinoma, whereas the non-nucleosidic pol $\alpha$ and pol $\delta$ inhibitor aphidicolin [11] failed to be introduced into tumour therapy while it still remains the standard substance in experimental pharmacology. Whereas cytarabine is active in leukaemia predominantly due to ribosyl reductase inhibition, $4^{\prime}$-thioFAC, similar to cytarabine and gemcitabine, potently inhibits pol $\alpha$, and less so the repair enzyme pol $\beta$ [12]. Aiming for actinic keratosis and squamous carcinoma therapy, selective non-nucleoside inhibitors of $\operatorname{pol} \alpha$, such as dehydroaltenusin [13], glycolipids from green tea and spinach [13-15] and acyl catechins [16, 17], have been described based on the results of preclinical testing strengthening the relevance of this target.

Since nucleoside and nucleotide analogue polymerase inhibitors have revolutionized the treatment of infections by some herpesviruses (herpes simplex virus, cytomegalovirus), hepadna viruses inducing viral hepatitis, and the human immunodeficiency virus (HIV), DNA polymerase inhibitors of the nucleoside type might also be of highest interest in actinic keratosis treatment. None of these antiviral drugs, however, have been considered in this indication so far.

To enable systematic access to the innovative target, we first modelled the structure of the active site of pol $\alpha$. This enzyme belongs to the DNA polymerase B family, which includes several eukaryotic and archaeal polymer- ases, as well as the viral adenovirus, herpes simplex virus type 1, RB69, T4 and T6 polymerases. Members of type B polymerase are of central importance in the accurate replication of the genetic material and despite diverse biological functions, the structural and chemical mechanisms of base incorporation seem to be highly conserved. Crystallographic structures of DNA polymerases indicate that these enzymes are composed of several functionally distinct domains and subdomains. A general feature of polymerase structures, a large cleft comprised of 3 subdomains, the 'fingers', the 'palm' and the 'thumb', can be characterized as a 'right hand' that is capable of holding DNA in its gaps [18-20]. The palm subdomain at the bottom of the cleft contains the catalytic site, while the finger and thumb subdomains form the walls of the cleft. Three different conformations of RB69 polymerase have been observed in crystal structures: the apo state without DNA, the editing mode forming a binary complex with DNA bound to the exonuclease site, and the replicating mode, a ternary complex with DNA and a deoxynucleotide triphosphate (dNTP) bound in the polymerase catalytic site. In the apo state and editing mode, the enzyme is in the 'open' form, showing a rotation of the fingers domain $60^{\circ}$ away from the palm. In the 'closed' conformation, 1 arginine and 2 lysines of the fingers domain are involved in hydrogen bonding to the phosphate groups of the incoming dNTP. DNA synthesis is mediated by transfer of a phosphoryl group from the incoming dNTP to the DNA 3'-OH, liberating pyrophosphate and forming a new DNA phosphoester bond. This reaction is catalyzed by a mechanism that involves 2 divalent metal ions, with the participation of 2 aspartic acid residues, which are structurally conserved among the different polymerase enzymes.

Molecular modelling [20] allowed us to identify selective nucleoside inhibitors [21]. The potential of pol $\alpha$ inhibition in skin cancer was derived from the influence of the new substances and the known pol $\alpha$ and pol $\delta$ inhibitor aphidicolin [11] in normal and transformed human keratinocytes. Since therapeutic failure with nucleoside analogues can result from a lack of enzymatic activation by kinases, degradation by phosphorylases or inducible drug transport out of the tumour cells, i.e., keratinocytes, the expression of relevant enzymes and transporters has to be taken into account, as well as the molecular weight and solubility of the agents. High molecular weight and poor solubility can seriously impair skin penetration and thus ask for adequate carrier systems to overcome the horny layer barrier. 


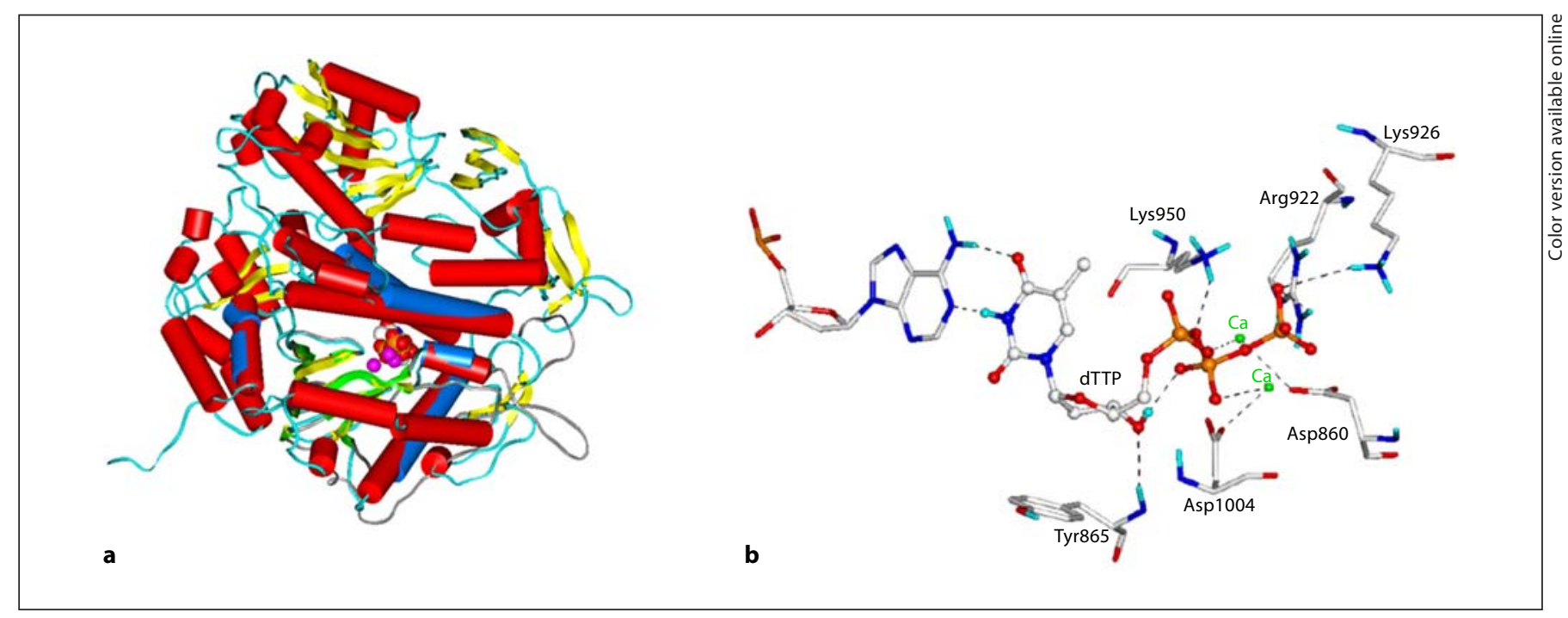

Fig. 1. Human DNA pol $\alpha$ model. a Superposition of the protein backbones of the template $(\alpha$-helices $=$ red, $\beta$-sheets $=$ yellow, loops = cyan) and the pol $\alpha$ model. The model contains the nucleotide binding domain only, consisting of a finger, palm and thumb region $(\alpha$-helices $=$ blue, $\beta$-sheets $=$ green, loops $=$ grey $)$. $\mathbf{b}$ A close-

\section{Molecular Modelling Studies}

Although crystal structures of several type B DNA polymerases are available [for a review on this field, see ref. 18, 19, 22], the three-dimensional structure of the human pol $\alpha$ had yet to be determined. Since a detailed three-dimensional model of the active site could facilitate the rational design of new inhibitors, a molecular model of the active site of pol $\alpha$ was constructed to study the structural requirements of pol $\alpha$ inhibition. The model for the tertiary structure of human pol $\alpha$ restricted to the 836-1102 region [20] contains, by analogy with other $B$ family polymerases of known structures, the fingers, palm and thumb regions of the enzyme.

\section{Generation of the Active Site of Human pol $\alpha$}

In the absence of experimental data, model building on the basis of the known three-dimensional structure of a homologous protein is at present the only reliable method to obtain structural information. For accurate structure prediction, this requires sequence identity of the target protein with templates of known structures of at least $30 \%$. According to alignment results, the palm, fingers and thumb domains of human pol $\alpha$ share 34\% identical residues and 49\% similar residues with T9N7 polymerase, but only $20 \%$ identical and $28 \%$ similar with RB69 polymerase. up view of the dTTP binding complex. Hydrogen bonds are shown as black dashed lines. Colour code of the ligand: carbon $=$ white, hydrogen $=$ cyan, oxygen $=$ red, nitrogen $=$ blue, phosphorus $=$ orange, calcium $=$ green. From Richartz et al. [20] with permission (colour only in online version).

Thus, T9N7 polymerase is the closer homologue, and should be a better choice for homology modelling. However, crystal coordinates were available only in the 'apo' (and therefore inactive) state, a conformation not useful for creating an active site model. Comparisons of the tertiary structures of homologous proteins have shown that three-dimensional structures have been much better conserved during evolution than protein primary structures. A close inspection of the three-dimensional crystal structures of the apo forms of T9N7 and RB69 polymerases indicated an exact match of the active sites, despite their low sequence identity of about $17 \%$. On the basis of these data, we concluded that RB69 polymerase seems to be a quite suitable template for modelling the pol $\alpha$ active site.

The resulting architecture of our model is very similar to the crystal structure of RB69 polymerase, as can be seen in figure 1 . The protein model was found to be stable, since restraints have not been necessary and the ternary complex with primer, template, deoxythymidine triphosphate (dTTP) and ions has remained fully intact during the molecular dynamics simulations. The dTTP binding site (fig. 1b) shows similar binding characteristics as seen in the crystal structure of RB69 polymerase: 3 conserved, positively charged residues, Arg922, Lys926, and Lys950 form salt bridges with the $\alpha$ - and $\gamma$-phosphate oxygens of the dTTP. The metal ions $\left(\mathrm{Ca}^{2+}\right.$ ions were taken accord- 
Fig. 2. The pol $\alpha$ /aphidicolin complex. The protein changes from the closed form (a) to the inactive open form (b) and the $\mathrm{Ca}^{2+}$ ions move away from the catalytic centre. Colour code: $\alpha$-helices $=$ red, $\beta$-sheets $=$ yellow, green, calcium ions = magenta, aphicolin = cyan. From Richartz et al. [20] with permission (colour only in online version).

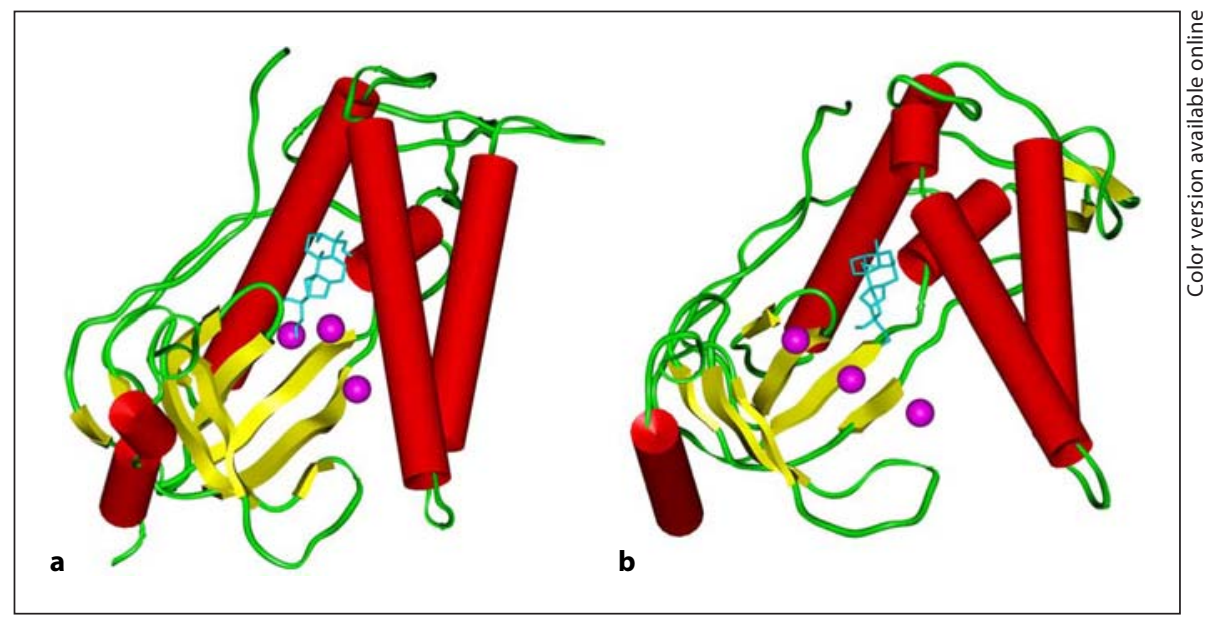

ing to the RB69 polymerase crystal structure) are ligated by Asp860 and Asp1004 and further complexed with the phosphate groups. Between the aromatic ring of Tyr865 and the ribose of dTTP, a stacking interaction is formed accompanied by a hydrogen bond between the amide hydrogen of Tyr865 and the oxygen of the $3^{\prime}-\mathrm{OH}$ group of the ribose.

\section{Development of pol $\alpha$ Inhibitors by Molecular Modelling}

Molecular dynamics simulations and docking of a series of known inhibitors were used to prove the active site model [20] and to propose strategies for designing new inhibitors. Docking results of a series of known nucleoside analogue inhibitors are consistent with experimental data and offer the possibility to elucidate structure activity data on a molecular level. Furthermore, from these studies we can explain, at least partially, the effect of aphidicolin on pol $\alpha$ in vitro. In molecular dynamics simulations of the active site model, aphidicolin occupies the catalytic centre (fig. 2), but acts in a not truly competitive manner with respect to nucleosides and nucleoside inhibitors, since it destabilizes the replicating 'closed' form and transfers the enzyme into the inactive 'open' conformation.

Docking of the natural substrate of pol $\alpha$ dTTP into the active site model revealed the formation of a hydrogen bond between the amide hydrogen of Tyr865 and the oxygen of the 3'-OH group of the ribose (fig. 1b) [20]. Consequently, a carbonyl function instead of the hydroxyl group in position $3^{\prime}$ (compound: HM-1-TP) would lead to an even better hydrogen bond acceptor, as illustrated in figure 3 .

Innovative Agents for Actinic Keratosis and Nanocarriers
Moreover, the binding mode of the known nucleotide analogue pol $\alpha$ inhibitor 2-butylanilino-dATP (BuP) [20] suggested the possibility of an additional hydrogen bond formation with Tyr865. Thus, introduction of a hydroxyl group in ortho position to the butyl moiety of the butylanilino group of $\mathrm{BuP}$ led to the new ligand $\mathrm{BuP}-\mathrm{OH}-\mathrm{TP}$. The results of molecular dynamics simulations indicated the existence of a stable hydrogen bond of the $\mathrm{OH}$ group with Tyr865 (fig. 3b). A series of BuP-OH analogues including those with non-linear side chain substituents (e.g. isohexyl side chain of the compound isoHex-OH) have been studied in detail with respect to their potential interaction geometries as well as affinities to the pol $\alpha$ active site.

In fact, molecular modelling studies also allowed a first step into the understanding of drug resistance mechanism for cytomegalovirus [23] and HIV [24] as well as the identification of new classes of HIV reverse transcriptase inhibitors $[25,26]$. This shows the high potential of this rather new methodological approach, given that the identified agents prove to be active.

\section{Cytotoxic Activity}

The thymidine analogue nucleoside HM-1 and the guanosine analogue $\mathrm{BuP}-\mathrm{OH}$ as well as related agents were synthesized by Reissig and coworkers [21], Institute of Chemistry and Biochemistry, Freie Universität Berlin, and subjected to pharmacological screening in monolayer cultures of normal human keratinocytes (NHK) [27] and transformed human keratinocytes (squamous cell carcinoma cell line SCC-25). Other than with molecular

Skin Pharmacol Physiol 2010;23:6-14 


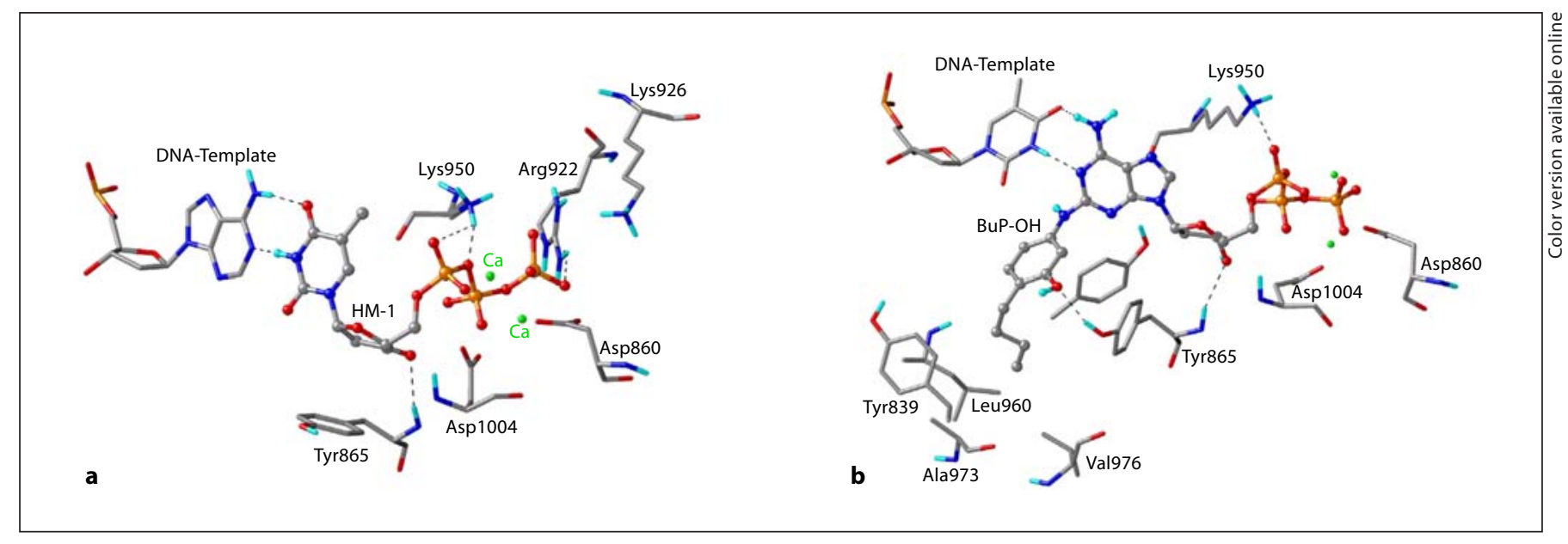

Fig. 3. Docking of HM-1-TP (a) and BuP-OH-TP (b) into the active side of pol $\alpha$ : hydrogen bond formation of HM-1-TP and the high hydroxyl group in ortho position to the butyl moiety of BuP-OH-TP with Tyr865. For colour code of the ligand, see figure 1. From Höltje et al. [21] with permission (colour only in online version).

modelling for which the triphosphates of the nucleoside analogues are necessary, cellular toxicity is investigated with the nucleoside analogues themselves. The triphosphates of the substances would be too hydrophilic to permeate the cell membrane and even more so the horny layer when applied topically.

The phosphorylation of the substances is done intracellularly by specific cellular kinases. To investigate if pol $\alpha$ inhibition may be an option for actinic keratosis and cutaneous squamous cell carcinoma therapy, the effects of the proposed compounds were compared to those of aphidicolin as well as to those of drugs approved for actinic keratosis (5-FU, diclofenac/hyaluronic acid) and the highly cytotoxic doxorubicin. The pyrophosphate analogue foscarnet blocking the pyrophosphate binding site of viral pol $\alpha$ served as negative control, which in fact proved inactive [21].

\section{Inhibition of DNA Synthesis}

As to be derived from thymidine incorporation, aphidicolin $10^{-6} \mathrm{M}$ - which was used for reference - completely inhibited DNA synthesis in $\mathrm{NHK}$ and the $\mathrm{IC}_{50}$ value was in the submicromolar range. Yet SCC-25 cells were less sensitive with an $\mathrm{IC}_{50}$ value in the micromolar range and a maximum inhibition of $57 \%$. The higher toxicity for NHK than for the tumour cell line in fact explains the failure of aphidicolin in clinical testing. The proposed compound $\mathrm{BuP}-\mathrm{OH}$ strongly inhibited the proliferation of normal keratinocytes as well. Yet other than with aphidicolin, SCC-25 cells were also strongly inhibited, toxic concentrations $\left(-\lg \mathrm{IC}_{50}\right)$ of $\mathrm{BuP}-\mathrm{OH}$ were close in NHK and SCC- 25 cells, the purine derivative, however, was less potent than aphidicolin (table 1). Nevertheless, $\mathrm{BuP}-\mathrm{OH}$ may mean a clear step forward over aphidicolin.

Besides aphidicolin, further reference substances were diclofenac used in the therapy of actinic keratosis and the cytotoxic agent doxorubicin. Causing 100\% inhibition doxorubicin did not differentiate between NHK and SCC-25 cells. As to be expected, pronounced cytotoxic effects were also seen with doxorubicin. Diclofenac inhibited DNA synthesis in NHK and in SCC-25 cells at identical concentrations ( $-\lg \mathrm{IC}_{50}$ about 4.3 ), but once more maximum inhibition in the tumour cell line was less than in normal keratinocytes. In mice, diclofenac failed to interfere with keratinocyte proliferation in a surgical wound model [28] while suppressing fibrosarcoma tumour growth [29].

The inhibitory effect of 5-FU and HM-1 on keratinocyte proliferation was not tested with the thymidine uptake assay. Exogenous thymidine probably antagonizes the thymidine analogues as well as the 5-FU-related depletion of endogenous dTTP, and thus exerts an antiproliferative effect.

\section{Viability}

Cell viability as determined by the MTT reduction test allowed to verify the data derived from the proliferation assay as well as to study 5-FU and HM-1 cytotoxicity. 5-FU was clearly less potent as compared to aphidicolin. 
This holds true both with respect to $-\lg \mathrm{IC}_{50}$ and maximum inhibition of viability. A minor preference in toxicity for transformed keratinocytes was detected (table 1) which may be relevant in the patient. All proposed nucleosides appeared active, yet lacked the potency of aphidicolin either with respect to both $-\lg \mathrm{IC}_{50}$ and maximum inhibition of viability (HM-1, isoHex-OH) or at least with respect to $-\lg \mathrm{IC}_{50}(\mathrm{BuP}-\mathrm{OH})$. In fact, the maximum inhibitory capacity of aphidicolin is even superseded by $\mathrm{BuP}-\mathrm{OH}$ regarding NHK and SCC- 25 cells. Differences in the modelled nucleosides to 5-FU, however, were less obvious and maximum effects were even more pronounced with BuP-OH. Most interestingly, a distinct selectivity for SCC-25 cells was observed when studying HM-1 (table 1). This agent appears particularly interesting for clinical testing, though a compound both selective for the tumour cell and highly active (at least corresponding to $\mathrm{BuP}-\mathrm{OH}$ ) should be of highest relevance.

Taken together, new DNA pol $\alpha$ inhibitors were created when applying molecular modelling methods. The nucleoside analogues are activated in transformed keratinocytes, but also in normal keratinocytes. Activity of these substances ranked as follows: aphidicolin $>\mathrm{BuP}$ $\mathrm{OH}>5-\mathrm{FU}>\mathrm{HM}-1$ when testing viability and ranked aphidicolin $>\mathrm{BuP}-\mathrm{OH}$ when studying proliferation [21]. The activation products appear to fit into the catalytic domain of the target enzyme which is of very restricted size [20]. Thus, we were able to predict structures of DNA pol $\alpha$ inhibitors, and the order of activity in general met our expectations. The model was predictive, given the ligands get unhindered access to the active site of the enzyme - which was not true for guanosine analogues having a non-linear substituent at the side chain (data not shown). The tumour cell specificity of HM-1, however, was not conceivable by molecular modelling. This selectivity may be linked to differences in nucleotide metabolism and transporters.

\section{Enzymes of Nucleotide Metabolism and Nucleotide Transporters}

The expression of enzymes and outward transporters for relevant nucleosides and nucleotides has to be considered when aiming for nucleoside analogue drugs. The cytosolic enzymes deoxycytidine kinase, thymidine kinase1 as well as the mitochondrial enzyme deoxyguanosine kinase were detected at the mRNA and protein level in NHK. This also holds true for the nucleoside inward transporter hENT-1 and the anionic outward transport-
Table 1. $-\lg \mathrm{IC}_{50}$ values (mean $\pm \mathrm{SE}$ ) derived from thymidine incorporation and viability assay (MTT test)

\begin{tabular}{|c|c|c|c|c|}
\hline & Aphidicolin & $5-\mathrm{FU}$ & HM-1 & $\mathrm{BuP}-\mathrm{OH}$ \\
\hline \multicolumn{5}{|c|}{ Viability $(48 h)$} \\
\hline NHK & $\begin{array}{l}8.26 \pm 0.41 \\
(44)\end{array}$ & $\begin{array}{l}5.08 \pm 0.48 \\
(41)\end{array}$ & $\begin{array}{l}\text { n.d. } \\
(23)\end{array}$ & $\begin{array}{l}4.58 \pm 0.24 \\
(66)\end{array}$ \\
\hline SCC-25 & $\begin{array}{l}6.29 \pm 0.29 \\
(62)\end{array}$ & $\begin{array}{l}6.01 \pm 0.28 \\
(42)\end{array}$ & $\begin{array}{l}4.74 \pm 0.34 \\
(47)\end{array}$ & $\begin{array}{l}5.05 \pm 0.37 \\
(65)\end{array}$ \\
\hline \multicolumn{5}{|c|}{ Proliferation (24h) } \\
\hline NHK & $\begin{array}{l}7.08 \pm 0.05 \\
(100)\end{array}$ & \multicolumn{2}{|c|}{$\begin{array}{l}\text { assay of }\left[{ }^{3} \mathrm{H}\right] \text { thymidine in- } \\
\text { corporation not possible } \\
\text { with thymidine analogues }\end{array}$} & $\begin{array}{l}5.59 \pm 0.27 \\
(100)\end{array}$ \\
\hline SCC-25 & $\begin{array}{l}6.07 \pm 0.18 \\
(58)\end{array}$ & & & $\begin{array}{l}5.07 \pm 0.38 \\
(87)\end{array}$ \\
\hline
\end{tabular}

Reduction was calculated after non-linear regression as $100-\mathrm{E}$. $\mathrm{E}=$ Activity at $10^{-4} \mathrm{M}$ in percent (see figures in parentheses); n.d. $=\lg \mathrm{IC}_{50}$ is not determinable with maximum inhibition $\leq 30 \%$ (from Höltje et al. [21]).

ers MRP- 4 and MRP-5 [21, 30]. The latter can cause nucleoside resistance, if overexpressed. Moreover, NHK express the organic anion transporters OATP-B, OATP-D and OATP-E, which are involved in drug influx [31]. SCC-25 cells hardly expressed the hENT-1 transporter as well as deoxycytidine kinase. For all other enzymes and transporters no relevant differences between normal keratinocytes and SCC-25 cells were seen [21]. The differences in nucleotide transporter and enzyme expression, however, do not explain the NHK preference for the nonnucleosidic aphidicolin nor the SCC-25 preference for the thymidine analogue HM-1.

\section{Skin Penetration}

By the topical treatment of skin diseases the active pharmaceutical ingredient makes contact with the target site before entering the systemic circulation which - in general - is mandatory for contact with non-target sites. Therefore, systemic side effects are reduced as compared to parenteral or oral drug administration, which is of major interest when applying drugs with limited tolerability as for example anticancer agents. Then surmounting the horny layer (stratum corneum) of the epidermis is the greatest challenge. To be well absorbed [32], a substance should have (1) a molecular mass less than $500 \mathrm{~g} / \mathrm{mol}$, (2) 
Fig. 4. Effects of nanoparticle size on dye penetration into pig skin: arbitrary pixel brightness values (ABU) following the application of lipid nanocapsules 60 (black columns), 90 (grey columns), and $185 \mathrm{~nm}$ (white columns) in diameter loaded with $0.004 \%$ nile red $(n=3)$. From Küchler et al. [38] with permission.

Fig. 5. Staining of pig skin following the application of $0.004 \%$ nile red-loaded cream (a), SLN (b) and CMS nanotransporters (c). The pictures are obtained by superposing normal light and fluorescence images of the same area. d The arbitrary pixel brightness values (ABU) corrected for background fluorescence (cream = black columns; SLN = grey columns; CMS nanotransporters = white columns). The inserted numbers give the respective enhancement of penetration over cream. The asterisk indicates significant differences ( $\mathrm{p} \leq 0.05)$. From Küchler et al. [37] with permission.
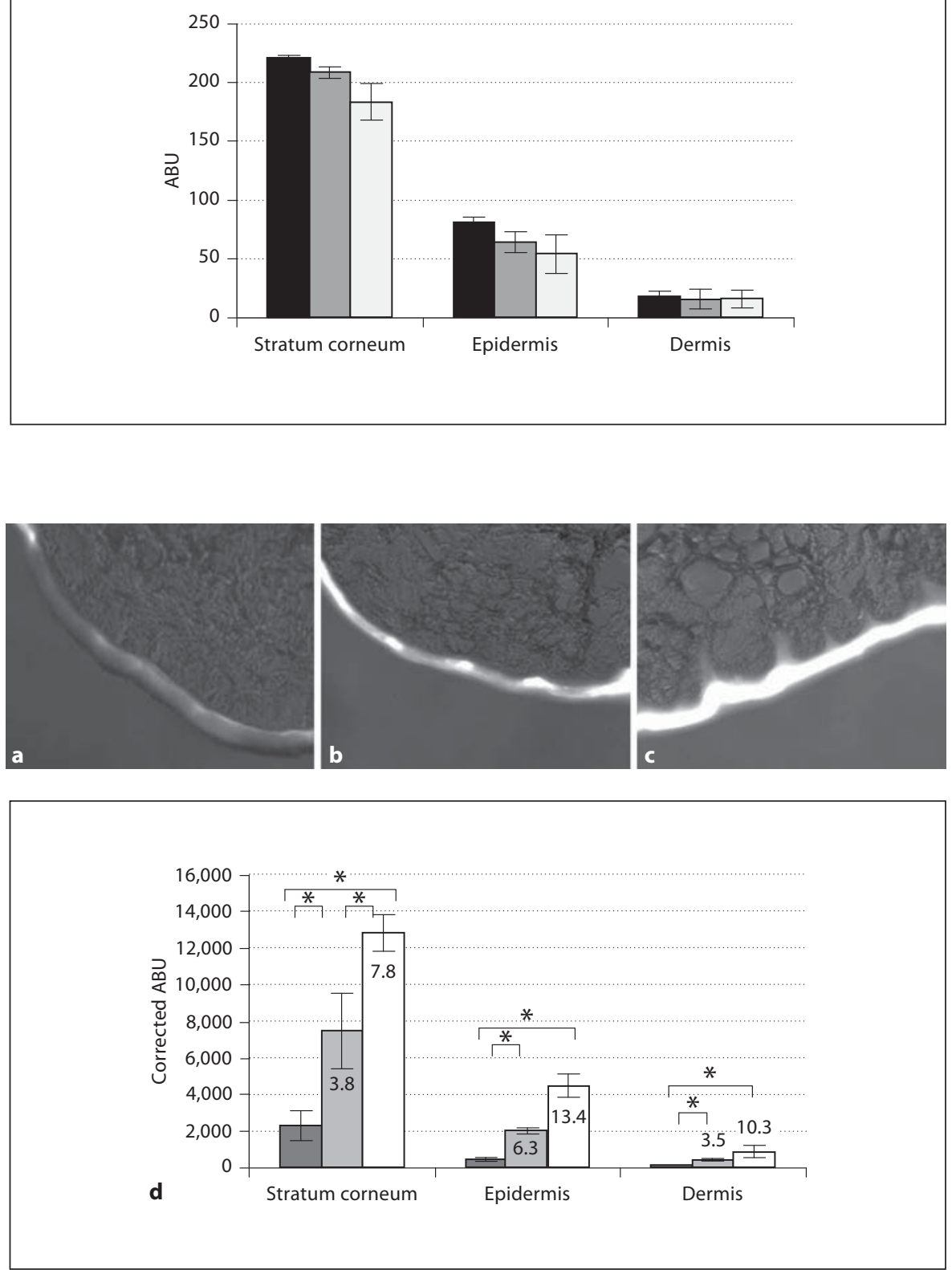

a low melting point, (3) adequate solubility in oil and water, and (4) an octanol:water partition coefficient $(\log \mathrm{P})$ of about 1 to 3 .

If this does not hold true for a drug molecule or if the parameters are close to the limits (e.g. calculated $\log \mathrm{P}$ of HM-1 -1.13; molecular mass of BuP-OH 414.47), colloidal carrier systems widely varying in structure can be used [32]. Whereas in the early days research in drug carrier systems focussed on liposomes, this today also in- volves the more stable solid lipid nanoparticles (SLN) made up from lipids solid at room temperature and nanostructured lipidic carriers built up from lipid mixtures solid and fluid at room temperature [for a review, see ref. 33]. These particles of about $200 \mathrm{~nm}$ in diameter stabilized by surfactants gained more and more interest over time not only for parenteral and oral use, but also for topical application on the skin. 
Detailed investigations into various lipidic systems (SLN, nanostructured lipidic carriers, nano-emulsions, lipid microparticles, nanocapsules) proved SLN to be most effective enhancing skin penetration 4 -fold to 8 fold over a cream used for reference [34-37]. Loadable are not only lipophilic agents such as steroids or the model dye nile red, but also hydrophilic agents - which are then located in the polymer shell and thus increase particle size considerably [38]. The size of particles ranging from 50 to $200 \mathrm{~nm}$ in diameter for skin penetration of the loaded compound appeared less relevant (fig. 4) [38]. The improved delivery by SLN results from mixing of the carrier lipid and skin surface lipids [37]. It is tempting to speculate that skin occlusion may add to the improved uptake [33].

Core-multishell (CMS) nanotransporters may be even more efficient. These improved (surface-modified) dendrimers were first described by Haag and Kratz [39] and Quadir et al. [40]. The primary aim was the design of $\mathrm{pH}-$ responsive carriers for the targeting of tumour cells [41]. CMS nanotransporters can enhance the skin penetration of lipophilic agents even 8- to 13-fold (fig. 5) [37].
To be suitable for pharmaceutical use, the application system has to be well tolerated. Whereas this can be a major problem with charged particles including dendrimers built up from a propylene amine core and lipid particles containing for example cetyl amine as a matrix component [42-47], SLN and CMS nanotransporters are well tolerated by keratinocyte monolayer cultures as well as reconstructed human epidermis [34, 48, 49] and thus may be suitable delivery systems for the nucleoside analogue pol $\alpha$ inhibitors. Therefore, the results of further preclinical and clinical testing should well prove rewarding.

\section{Acknowledgements}

The authors thank Riemser Arzneimittel, Riems, and the German Ministry of Education and Research, Bonn (FK 13N9062), for financial support.

\section{References}

1 Queille S, Luron L, Spatz A, Avil MF, Ribrag V, Duvillard P, Hiesse C, Sarasin A, Armand JP, Daya-Grosjean L: Analysis of skin cancer risk factors in immunosuppressed renal transplant patients shows high levels of UVspecific tandem CC to TT mutations of the p53 gene. Carcinogenesis 2007;28:724-731.

2 Madkan VK, Cook-Norris RH, Steadman MC, Arora A, Mendoza N, Tyring SK: The oncogenic potential of human papillomaviruses: a review on the role of host genetics and environmental cofactors. Br J Dermatol 2007;57:228-241.

3 Dianzani C, Pierangeli A, Chiricozzi A, Avola A, Degener AM: Cutaneous human papillomaviruses as recurrence factor in actinic keratoses. Int J Immunopathol Pharmacol 2008;21:145-153.

4 Michel A, Kopp-Schneider A, Zentgraf H, Gruber AD, de Villers EM: E6/E7 expression of human papillomavirus type 20 (HPV-20) and HPV-27 influences proliferation and differentiation of the skin in UV-irradiated SKH-hrl transgenic mice. J Virol 2006;80: 1153-1164.

5 Jorizzo J: Topical treatment of actinic keratosis with fluorouracil: is irritation associated with efficacy? J Drugs Dermatol 2004;3: 21-26.
6 Rhodes LE, de Rie M, Enstrom Y, Groves R, Morken T, Goulden V, Wong GA, Grob JJ, Varma S, Wolf P: Photodynamic therapy using topical methyl aminolevulinate vs. surgery for nodular basal cell carcinoma: results of a multicenter randomized prospective trial. Arch Dermatol 2004;140:17-23.

7 Pariser D, Loss R, Jarratt M, Abromovits W, Spencer J, Geronemus R, Bailin P, Bruce S: Topical methyl-aminolevulinate photodynamic therapy using red light-emitting diode light for treatment of multiple actinic keratoses: a randomized, double-blind, placebo-controlled study. J Am Acad Dermatol 2008;59:569-576.

8 Wolf JE Jr, Taylor JR, Tschen E, Kang S: Topical 3.0\% diclofenac in $2.5 \%$ hyaluronan gel in the treatment of actinic keratoses. Int J Dermatol 2001;40:709-713.

9 Rivers JK, Arlette J, Shear N, Guenther L, Carey W, Poulin Y: Topical treatment of actinic keratoses with 3.0\% diclofenac in 2.5\% hyaluronan gel. Br J Dermatol 2002;146:94100.

10 Lebwohl M, Dinehart S, Whiting D, Lee PK, Tawfik N, Jorizzo J, Lee JH, Fox TL: Imiquimod $5 \%$ cream for the treatment of actinic keratosis: results from two phase III, randomized, double-blind, parallel group, vehicle-controlled trials. J Am Acad Dermatol 2004;50:714-721.
11 O'Dwyer PJ, Moyer JD, Suffness M, Harrison SD Jr, Cysyk R, Hamilton TC, Plowman $\mathrm{J}$ : Antitumor activity and biochemical effects of aphidicolin glycinate (NSC 303812) alone and in combination with cisplatin in vivo. Cancer Res 1994;54:724-729.

12 Miura S, Izuta SI: DNA polymerases as targets of anticancer nucleosides. Curr Drug Targets 2004;5:191-195.

13 Maeda N, Kokai Y, Ohtani S, Sahara H, Kuriyama I, Kamisuki S, Takahashi S, Sakaguchi K, Sugawara F, Yoshida H, Sato N, Mizushina Y: Anti-tumor effects of dehydroaltenusin, a specific inhibitor of mammalian DNA polymerase alpha. Biochem Biophys Res Commun 2007;352:390-396.

14 Kuriyama I, Musumi K, Yonezawa Y, Takemura M, Maeda N, Iijima H, Hada T, Yoshida $\mathrm{H}$, Mizushina Y: Inhibitory effects of glycolipids fraction from spinach on mammalian DNA polymerase activity and human cancer cell proliferation. J Nutr Biochem 2005;16: 594-601.

15 Maeda N, Yoshida H, Sato N, Mizushina Y, Kokai Y, Ohtani S, Sahara H, Hada T, Ishimaru C, Kuriyama I, Yonezawa Y, Iijima H: Anti-tumor effects of the glycolipids fraction from spinach which inhibited DNA polymerase activity. Nutr Cancer 2007;57:216223. 
16 Matsubara K, Saito A, Tanaka A, Nakajima N, Akagi R, Mori M, Mizushina Y: Catechin conjugated with fatty acid inhibits DNA polymerase and angiogenesis. DNA Cell Biol 2006;25:95-103.

17 Matsubara K, Saito A, Tanaka A, Nakajima N, Akagi R, Mori M, Mizushina Y: Epicatechin conjugated with fatty acid is a potent inhibitor of DNA polymerase and angiogenesis. Life Sci 2007;80:1578-1585.

18 Alba M: Replicative DNA polymerases. Genome Biol 2001;2:REVIEWS3002.

19 Steitz TA: DNA polymerases: structural diversity and common mechanisms. J Biol Chem 1999;274:17395-17398.

20 Richartz A, Höltje M, Brandt B, SchäferKorting M, Höltje H-D: Targeting human polymerase $\alpha$ for the inhibition of keratinocyte proliferation. 1. Homology model, active site architecture and ligand binding. J Enzyme Inhib Med Chem 2008;23:94-100.

21 Höltje M, Richartz A, Zdrazil B, Schwanke A, Dugovic B, Murruzzu C, Reissig HU, Korting HC, Kleuser B, Höltje HD, SchäferKorting M: Human polymerase $\alpha$ inhibitors for skin tumors. 2. Modelling, synthesis and influence on normal and transformed keratinocytes of new thymidine and purine derivatives. J Enzyme Inhib Med Chem, in press.

22 Keller DJ, Brozik JA: Framework model DNA polymerases. Biochemistry 2005;44:68776888.

23 Shi R, Azzi A, Gilbert C, Boivin G, Lin SX: Three-dimensional modelling of cytomegalovirus DNA polymerase and preliminary analysis of drug resistance. Proteins 2006; 64:301-307.

24 Ren J, Stammers DK: Structural basis for drug resistance mechanisms for non-nucleoside inhibitors of HIV reserve transcriptase. Virus Res 2008;134:157-170.

25 Spallarossa A, Cesarini S, Ranise A, Ponassi $\mathrm{M}$, Unge T, Bolognesi M: Crystal structures of HIV-1 reverse transcriptase complexes with thiocarbamate non-nucleoside inhibitors. Biochem Biophys Res Commun 2008; 365:764-770.

26 Ren J, Chamberlain PP, Stamp A, Short SA, Weaver KL, Romines KR, Hazen R, Freeman A, Ferris RG, Andrews CW, Boone L, Chan JH, Stammers DK: Structural basis for the improved drug resistance profile of new generation benzophenone non-nucleoside HIV-1 reverse transcriptase inhibitors. J Med Chem 2008;51:5000-5008.

27 Gysler A, Lange K, Korting HC, SchäferKorting M: Prednicarbate biotransformation in human foreskin keratinocytes and fibroblasts. Pharm Res 1997;14:793-797.
28 Fedorocko P, Hoferova Z, Hofer M, Brezani $\mathrm{P}$ : Administration of liposomal muramyl tripeptide phosphatidylethanolamine (MTP$\mathrm{PE}$ ) and diclofenac in the combination attenuates their anti-tumor activities. Neoplasma 2003;50:176-184.

29 Haberland A, Schreiber S, Santos Maia C, Rübbelke MK, Schaller M, Korting HC, Kleuser B, Schäfer-Korting M: The impact of skin viability on drug metabolism and permeation - BSA toxicity on primary keratinocytes. Toxicol In Vitro 2006;20:347-354.

30 Baron JM, Höller D, Schiffer R, Frankenberg S, Neis M, Merk HF, Jugert FK: Expression of multiple cytochrome p450 enzymes and multidrug resistance-associated transport proteins in human skin keratinocytes. J Invest Dermatol 2001;116:541-548.

31 Schiffer R, Neis M, Höller D, Rodriguez F, Geier A, Gartung C, Lammert F, Dreuw A, Zwadlo-Klarwasser G, Merk H, Jugert F, Baran JM: Active influx transport is mediated by members of the organic transporting polypeptide family in human epidermal keratinocytes. J Invest Dermatol 2003;120: 285-291.

32 Korting HC, Schäfer-Korting M: Carriers in the topical treatment of skin disease; in Schäfer-Korting M (ed): Handbook of Experimental Pharmacology/Drug Delivery. Heidelberg, Springer, in press.

33 Müller RH, Petersen RD, Hommoss A, Pardeike J: Nanostructured lipid carriers (NLC) in cosmetic dermal products. Adv Drug Deliv Rev 2007;59:522-530.

34 Santos Maia C, Mehnert W, Schaller M Korting HC, Gysler A, Haberland A, SchäferKorting M: Drug targeting by solid lipid nanoparticles for dermal use. J Drug Target 2002;10:489-495.

35 Lombardi Borgia S, Regehly M, Sivaramakrishnan R, Mehnert W, Korting HC, Danker K, Röder B, Kramer KD, Schäfer-Korting M: Lipid nanoparticles for skin penetration enhancement - correlation to drug localization within the particle matrix as determined by fluorescence and parelectric spectroscopy. J Control Release 2005;110:151-163.

36 Štecová J, Mehnert W, Blaschke T, Kleuser B, Sivaramakrishnan R, Zouboulis CC, Seltmann H, Korting HC, Kramer KD, SchäferKorting M: Cyproterone acetate loading to lipid nanoparticles for topical acne treatment: particle characterisation and skin uptake. Pharm Res 2007;25:991-1000.

37 Küchler S, Radowski MR, Blaschke T, Dathe M, Plendl J, Haag R, Schäfer-Korting $M$, Kramer KD: Nanoparticles for skin penetration enhancement - A comparison of a dendritic core-multishell-nanotransporter and solid lipid nanoparticles. Eur J Pharm Biopharm 2009;71:243-250.

38 Küchler S, Abdel-Mottaleb M, Lamprecht A,
Radowski MR, Haag R, Schäfer-Korting M: Influence of nanocarrier type and size on skin delivery of hydrophilic agents. Int J Pharm 2009;377:169-172.

39 Haag R, Kratz F: Polymer therapeutics: concepts and applications. Angew Chem Int Ed Engl 2006;45:1198-1215.

40 Quadir MA, Radowski MR, Kratz F, Licha K, Hauff P, Haag R: Dentritic multishell architectures for drug and dye transport. J Control Release 2008;132:289-294.

41 Xu S, Luo Y, Graeser R, Warnecke A, Kratz F, Hauff P, Licha K, Haag R: Development of $\mathrm{pH}$-responsive core-shell for delivery of therapeutic and diagnostic agents. Bioorg Med Chem Lett 2009;19:1030-1034

42 Stasko NA, Johnson CB, Schoenfisch MH, Johnson TA, Holmuhamedov EL: Cytotoxicity of polypropylenimine dendrimer conjugates on cultured endothelial cell. Biomacromolecules 2007;8:3853-3859.

43 Hong S, Bielinska AU, Mecke A, Keszler B, Beals JL, Shi X, Balogh L, Orr BG, Baker JR, Banaszak Holl MM: Interaction of poly(amidoamine) dendrimers with supported lipid bilayers and cells: hole information and the relation to transport. Bioconjug Chem 2004:15:774-782.

44 Moghimi SM, Szebeni J: Stealth liposomes and long circulating nanoparticles: critical issues in pharmacokinetics, opsonization and protein-binding properties. Prog Lipid Res 2003;42:463-478.

45 Schöler N, Olbrich C, Tabatt K, Müller RH, Hahn H, Liesenfeld O: Surfactant, but not the size of solid lipid nanoparticles (SLN) influences viability and cytokine production of macrophages. Int J Pharm 2001;221:5767.

46 Weyenberg W, Filev P, Van den Plas D, Vandervoort K, De Smet P, Sollie A, Ludwig A: Cytotoxicity of submicron emulsions and solid lipid nanoparticles for dermal application. Int J Pharm 2007:337:291-298.

47 Müller RH, Rühl D, Runge S, Schulze-Forster K, Mehnert W: Cytotoxicity of solid lipid nanoparticles as a function of the lipid matrix and the surfactant. Pharm Res 1997;14: 458-462.

48 Schöler N, Hahn H, Müller RH, Liesenfeld O: Effect of lipid matrix and size of solid lipid nanoparticles (SLN) on the viability and cytokine production of macrophages. Int $\mathrm{J}$ Pharm 2002;231:167-176.

49 Wolf N, Küchler S, Radowski MR, Blaschke T, Kramer KD, Weindl G, Kleuser B, Haag R, Schäfer-Korting M: Influences of opioids and nanoparticles on in vitro wound healing models. Eur J Pharm Biopharm 2009;73:3442 . 